\title{
Age of appearance of circadian rhythm in salivary cortisol values in infancy
}

\author{
D A PRICE, G C CLOSE, AND B A FIELDING \\ Department of Child Health, Royal Manchester Children's Hospital, Manchester
}

SUMMARY Samples of saliva (4 in 24 hours), collected at monthly intervals for the first 6 months of life in 8 term infants by their mothers, were analysed for cortisol by radioimmunoassay. Values in the first month were more variable, daily mean values were greater, and amplitudes of variation were greater than in subsequent months. The circadian rhythm appeared by the third month.

The age at which the 'adult' circadian rhythm of cortisol secretion emerges is difficult to ascertain for obvious ethical reasons and the few data available all conflicting. Franks ${ }^{1}$ measured plasma 17 -hydroxycorticosteroids at 8 am and $8 \mathrm{pm}$ in children and concluded that the 'adult' pattern emerged between 1 and 3 years. A study, however, based on urine collections every 3 hours throughout the day in male infants suggested a diurnal rhythm of excretion of 17-hydroxycorticosteroids by day 26 of life. ${ }^{2}$ The most complete study, by Zurbrügg, ${ }^{3}$ who took blood samples every 4 hours from 6 neonates (3-9 days old), from 5 infants (1-6 months old), and from 11 children ( $1 \frac{1}{2}-11 \frac{1}{2}$ years old), concluded that 12 hourly cycles of plasma cortisol occurred in the neonatal period and a 24 hour cycle in the second year of life. The mean daily plasma cortisol concentration and mean amplitudes of variation were comparable in all age groups.

Mixed salivary cortisol values closely reflect plasma free cortisol values ${ }^{4}$ and a circadian rhythm has been identified in adults ${ }^{56}$ and children. ${ }^{7}$ To determine when the circadian rhythm appeared an ethically acceptable longitudinal study was carried out in 8 normal infants in their homes, using small salivary samples taken by mothers for cortisol estimation.

\section{Patients and methods}

Eight term neonates ( 4 boys and 4 girls), whose mothers agreed to participate in the study, were selected. Four deliveries were unassisted, 1 was forceps assisted, and 3 were by caesarian section. All babies were of normal birthweight $(2 \cdot 95-3 \cdot 5 \mathrm{~kg})$ except 1 who was light for gestational age $(2.3 \mathrm{~kg}$ at 41 weeks). None of the babies had postnatal problems and all were well during the study. Five were breast fed. Mothers were asked at what age the night feed was omitted and babies slept throughout the night.

Saliva collection. Mothers were requested to provide 4 samples in a 24 hour period during weeks $1,4,8$, $12,16,20$, and 24 of life. Several collections requested for week 24 were made between weeks 24 and 30 . The first sample was requested at a convenient time between $6 \mathrm{am}$ and $8 \mathrm{am}$, the second between $11 \mathrm{am}$ and $1 \mathrm{pm}$, the third between $3 \mathrm{pm}$ and $6 \mathrm{pm}$, and the final sample between $10 \mathrm{pm}$ and $12 \mathrm{pm}$. Mothers were instructed to place a small citric acid crystal on the infant's tongue and aspirate 1-3 ml of saliva with a disposable mucus extractor over the next few minutes. ${ }^{8}$ Saliva was transferred to small plastic capped bottles (with the times recorded) that were sent to the laboratory on the following day and stored at $-20^{\circ} \mathrm{C}$ until analysed.

The project was approved by the local ethical committee. On consultation during and after the study mothers did not feel that the babies were distressed by the procedure.

Cortisol assay. Cortisol was estimated by radioimmunoassay in $60 \mu \mathrm{l}$ samples of saliva without prior extraction. The method is described elsewhere. ${ }^{6}$ Values for normal children aged 5-15 years, established in our laboratory for clinical work, range from 3.3 to $26.6 \mathrm{nmol} / \mathrm{l}$ (mean $\pm \mathrm{SD}, 11 \cdot 0 \pm 6.0$ $\mathrm{nmol} / \mathrm{l})$ at 8 am and from 0 to $7 \cdot 1 \mathrm{nmol} / 1$ (mean $\mathrm{SD}, 1.6 \pm 1.5 \mathrm{nmol} / \mathrm{l}$ ) at $8 \mathrm{pm}$ (unpublished data).

\section{Calculations}

The daily mean value of salivary cortisol for each child at each week was calculated. The amplitude of variation-the difference between the highest and 
lowest values of salivary cortisol in a 24 hour period-was estimated for each child at each week. Daily mean values and amplitudes compared using a 2-tailed Student's $t$ test.

\section{Results}

Range of salivary cortisol values. All observations are recorded in Fig. 1, which shows variable values for salivary cortisol during weeks 1 and 4 , with frequent high values in the evening. By week 12 the range of evening values $(10 \mathrm{pm}-12 \mathrm{am})$ fell to $0-7.0 \mathrm{nmol} / \mathrm{l}-$ comparable to the values in older children.

Daily mean salivary cortisol values. If the daily mean values for weeks 1 and 4 are compared with those for weeks 8 and 12 (Table) there is a significant fall $(P<0.001)$. Similarly, the daily mean values for weeks 16 and 20 are significantly less $(P<0.001)$ than
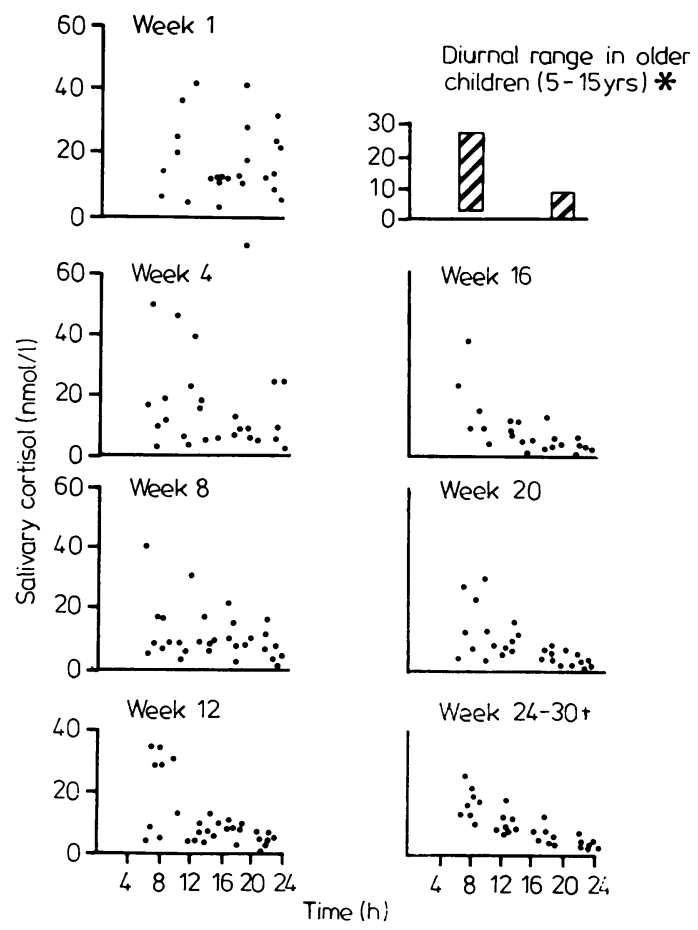

Fig. 1 Development of circadian rhythm in salivary cortisol concentrations during first 6 months of life in 8 normal babies.

\footnotetext{
*Data on older children (girl, left; boy, right) represented for comparison and perspective. †Data combined for weeks 24 to 30 .

Conversion: SI to traditional units--salivary cortisol: $1 \mathrm{nmol} / \mathrm{l} \approx 0.36 \mathrm{mg} / 100 \mathrm{ml}$.
}

Table Salivary cortisol concentrations (mean $(S D)$ ) in the first 6 months of life

\begin{tabular}{|c|c|c|}
\hline \multirow[t]{2}{*}{ Week } & $\begin{array}{l}\text { Daily mean cortisol } \\
\text { concentration }(\mathrm{nmol} / \mathrm{l})\end{array}$ & Amplitude of cortisol \\
\hline & mean $(S D)$ & mean $(S D)$ \\
\hline 1 & $20 \cdot 0(9 \cdot 1)$ & $25 \cdot 0(16 \cdot 1)$ \\
\hline 4 & $16.6(9.5)$ & $26.4(20.4)$ \\
\hline 8 & $10.7(3.5)$ & $15 \cdot 8(12 \cdot 1)$ \\
\hline 12 & $10.9(3.9)$ & $17.0(10 \cdot 2)$ \\
\hline 16 & $9 \cdot 0(4 \cdot 7)$ & $14.0(11.4)$ \\
\hline & $7.7(3.0)$ & $12.4(8.8)$ \\
\hline $24-30 *$ & $8 \cdot 6(2 \cdot 1)$ & $12.7(5.6)$ \\
\hline
\end{tabular}

*Data combined for weeks 24 to 30.

Conversion: SI to traditional units-salivary cortisol $1 \mathrm{nmol} / 1 \approx 0.36$ $\mathrm{mg} / 100 \mathrm{ml}$.

those for weeks 8 and 12. There is no significant difference between the daily mean values for weeks 24 and 30, compared with those of weeks 16 and 20.

Amplitude of variation. There is a significant decrease in size of amplitude between weeks 1 and 4 compared with weeks 8 and $12(\mathrm{P}<0.01)$ (Table). There is, however, no significant fall when weeks 8 and 12 are compared with weeks 16 and 20.

Circadian rhythm. Individual values ( 2 examples given in Fig. 2) show that the 'adult' pattern of a

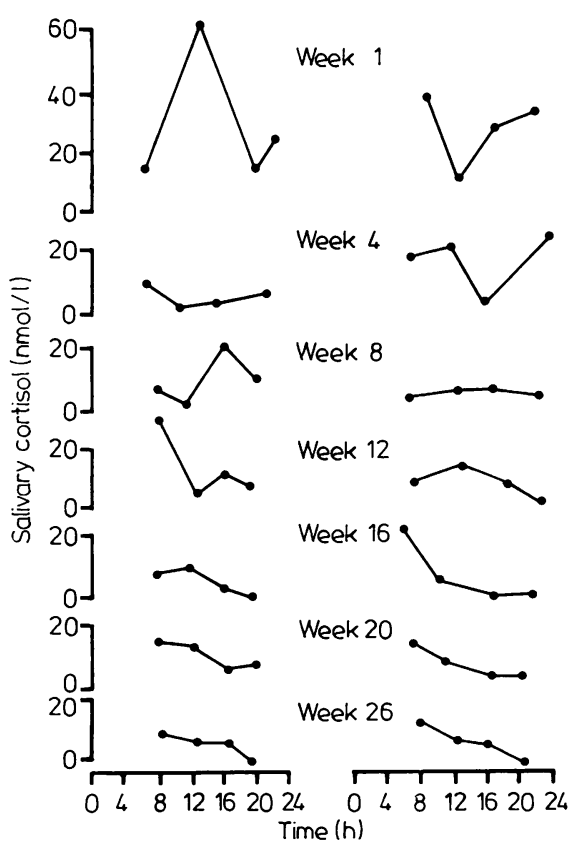

Fig. 2 Salivary cortisol concentrations in 2 normal babies (left girl, right boy). Circadian rhythm present in the girl at 12 weeks and in the boy at 16 weeks. 
higher value in the morning than in the evening and a steady decline throughout the day emerged (and remained) at 12 weeks in 5 babies, 8 weeks in 1,16 weeks in 1 , and 20 weeks in 1 . The combination of all observations (Fig. 1) shows that this rhythm emerged in the group as a whole at 12 weeks.

Relation to sleep pattern. Mothers observed that their babies slept through the night $(10 \mathrm{pm} / 12 \mathrm{pm}$ to $6 \mathrm{am} / 8 \mathrm{am})$ at $6,8,10$ ( 2 babies), 12 ( 2 babies), 13, and 14 weeks. The onset of this sleep pattern preceded the observed appearance of circadian cortisol rhythm in 5 babies, coincided with its appearance in 1 , and followed its appearance in 2.

\section{Discussion}

From the combined data shown in Fig. 1 it seems that the circadian rhythm of cortisol secretion is established by the twelfth week of life. This is contrary to the suggestion of Franks ${ }^{1}$ that the rhythm does not appear until 1-3 years of age, but supports the limited data in published reports ${ }^{2} \mathbf{3}$ for circadian rhythm appearing early. Zurbrügg ${ }^{3}$ considers that there are 2 peaks in the day in the first months of life, but our findings do not support that view. The pattern of regular unbroken night sleep preceded or coincided with the development of the circadian cortisol rhythm in 6 out of 8 infants. Such a relation, however, is not necessarily causal, nor would it be wise to generalise from such small numbers. That the values were more variable in the morning than in the evening supports the view that the circadian rhythm consists of shorter episodes of secretion of cortisol $^{8}$ (secondary to episodic secretion of adrenocorticotrophic hormone (ACTH)) and it is possible to sample at the peak or trough of such a fluctuation. The appearance of a limited range of values in the evening is therefore an easier event to identify, and that trend is already seen at 8 weeks.

The mean daily concentration of salivary cortisol and the amplitude of variation of salivary cortisol is greater in the first month of life than in subsequent months, though Zurbrügg ${ }^{3}$ found no important difference in the mean daily plasma cortisol concentrations of neonates and thought that there was a trend of increasing amplitude of variation with age. These discrepancies may be accounted for by the fact that salivary cortisol values reflect the amount of free cortisol in the plasma rather than the total amount of cortisol in the plasma, ${ }^{4}$ and thus salivary cortisol values are more useful in understanding episodic ACTH secretion.

A further advantage of salivary sampling is that normal infants may be studied in their own home without harm or distress to the infants. Indeed, apart from ethical considerations, stress from venepuncture is counterproductive to the study of adrenocortical function.

Differences in salivary flow rate or duration of the collection period make no appreciable difference to cortisol values. ${ }^{6}$ There are limitations, however, to the method and the study. It is not practicable to sample during sleep and disturb the infant, and the frequency of sampling in this study may have been too low. We had to balance the wish for sampling as often as possible against invasion on the time and goodwill of the parents.

This study provides the only longitudinal observations on the development of the circadian rhythm of cortisol secretion in infancy and it is important therefore that further studies are carried out. Comparison of various groups of neonates, such as preterm infants, could be undertaken using similar techniques and may provide valuable information on understanding the response to stress in these infants.

We thank the mothers of these infants for their ready cooperation; Dr M J Robinson for access to his patients; Professor IB Houston for support; the Salford Department of Medical Illustration; and Mrs K Cordwell.

\section{References}

1 Franks RC. Diurnal variation of plasma 17-hydroxycorticosteroids in children. $J$ Clin Endocrinol 1967; 27: 75-8.

2 Martin-Du-Pan R, Vollenweider L. L'apparition du rhythme circadien des 17-hydroxy-steroides chez le nourrisson. Praxis 1967; 56: 138-44.

3 Zurbrügg RP. Hypothalamic-pituitary-adrenocorticol regulation: a contribution to its assessment, development, and disorders in infancy and childhood with special reference to plasma cortisol circadian rhythm. Monographs in Pediatrics Vol 7. Basel: Karger, 1976: 12-17.

4 Umeda T, Hiramatsu R, Iwaoka T, Shimada T, Miura F, Sato T. Use of saliva for monitoring unbound free cortisol levels in serum. Clin Chim Acta 1981; 110: 245-53.

5 Walker RF, Riad-Fahmy D, Read GF. Adrenal status assessed by direct radioimmunoassay of cortisol in whole saliva or parotid saliva. Clin Chem 1978; 24: 1460-3.

6 Ferguson DB, Price DA, Wallace S. Effects of physiological variables on the concentration of cortisol in human saliva. Adv Physiol Sci 1980; 28: 301-11.

7 Bacon CJ, Mucklow JC, Saunders A, Rawlins MD, Webb JKG. A method for obtaining saliva samples from infants and young children. Br J Clin Pharmacol 1978; 5: 89-90.

8 Mills JN. Development of circadian rhythms in infancy In: Davis JA, Dobbing J, eds. Scientific foundations of paediatrics. London: Heinemann, 1974: 758-72.

Correspondence to Dr D A Price, Department of Child Health, Royal Manchester Children's Hospital, Pendlebury, Manchester M27 1HA.

Received 3 March 1983 